\title{
Online monitoring of the nanoscale zero-valent iron process for trichloroethylene wastewater treatment
}

\author{
R.-F. Yu $\cdot$ F.-H. Chi $\cdot$ W.-P. Cheng • \\ M.-H. Wang
}

Received: 18 May 2013/Revised: 2 January 2014/ Accepted: 10 March 2014/Published online: 9 April 2014

(C) Islamic Azad University (IAU) 2014

\begin{abstract}
In this study, a batch-type, nanoscale, zerovalent iron process was used to treat trichloroethylene wastewater. Variations in oxidation-reduction potential (ORP) and $\mathrm{pH}$ in the reactor were monitored online for use in developing the model for process control. After the addition of nanoscale, zero-valent iron, the $\mathrm{pH}$ value increased rapidly, from 5.0-6.0 to around 8.5-9.5, whereas the ORP decreased dramatically, from around $300 \mathrm{mV}$ to -700 to $-800 \mathrm{mV}$. The degradation of trichloroethylene reached equilibrium at a reaction time of about $120 \mathrm{~min}$. The use of a dose of $1.5 \mathrm{~g} / \mathrm{L}$ to treat an influent that had a trichloroethylene concentration of $50 \mathrm{mg} / \mathrm{L}$ resulted in a removal efficiency of $94 \%$. Two models, i.e., a multiple regression model and an artificial neural network (ANN) model, were used to develop the control model to predict the trichloroethylene removal efficiencies. Both the regression model and the ANN model performed precise prediction results for the trichloroethylene removal efficiencies, with correlation coefficients of about 0.87 and 0.98 , respectively, resulting in great potential for controlling the trichloroethylene removal.
\end{abstract}

Keywords Artificial neural network - Monitoring and control $\cdot$ Nanoscale zero-valent iron · Oxidation-reduction potential $\cdot \mathrm{pH} \cdot$ Trichloroethylene

R.-F. Yu ( $₫)$ · W.-P. Cheng · M.-H. Wang

Department of Safety, Health and Environmental Engineering,

National United University, Miao-Li 360, Taiwan, ROC

e-mail: rfyu@nuu.edu.tw

F.-H. Chi

Department of Environmental Engineering, Kun-Shan

University of Technology, T'ai-nan 710, Taiwan, ROC

\section{Introduction}

Trichloroethylene (TCE) is discharged in the industrial wastewater produced by metal degreasing processes, electronic processes, and dry cleaning, which are most critical sources for the dense, non-aqueous-phase liquid (DNAPL) contaminants in groundwater that are difficult to remediate (Cho and Choi 2010; Haest et al. 2012; Wang et al. 2012). Industrial wastewaters that contain TCE typically have been treated by various chemical technologies, including chemical adsorption and oxidation processes (West et al. 2008). However, the nanoscale zero-valent iron (nZVI) process has emerged as one of the most innovative and effective technologies for soil and groundwater remediation, as well as for treating industrial wastewaters, due to its strong redox potential and large specific surface area (Crane and Scott 2012; Hua et al. 2012). The nZVI process has been used to reduce various pollutants, including chlorinated hydrocarbons (Lookman et al. 2004; He et al. 2007; Smuleac et al. 2011), nitrochlorobenzene (Dong et al. 2011), dyes (Lin et al. 2008; Shu et al. 2007, 2010; Moon et al. 2011), heavy metals (Uzuma et al. 2008; Zhang et al. 2010; Shi et al. 2010; Dua et al. 2012), and nitrites (Ryu et al. 2011; Liu et al. 2012). The nZVI process also has been used to inactivate microbes and remove antibiotics from aqueous effluents (Diao and Yao 2009; Ghauch et al. 2009). However, investigations concerning process monitoring and control of the nZVI process are relatively rare.

The monitoring of oxidation-reduction potential (ORP), dissolved oxygen (DO), and $\mathrm{pH}$ provides economical, flexible, and effective control parameters for the various wastewater treatment processes (Chang et al. 2004; Olsson 2012; Zanetti et al. 2012) that have been applied successfully to control systems that remove biological nutrients 
(Fuerhacker et al. 2000; Yu et al. 2000; Saby et al. 2003; Won and Ra 2011; Martin de la Vega et al. 2012), infectious organisms ( $\mathrm{Yu}$ et al. 2009a; Lin et al. 2012), and advanced oxidation processes (AOPs) (Gernjak et al. 2006; $\mathrm{Yu}$ et al. 2009b; Lucas and Peres 2009; Ortega-Gomez et al. 2012). Due to the fact that nZVI has a high reduction potential, using the nZVI process to degrade TCE in aqueous solutions will decrease the ORP values significantly in the reactor. In addition, the overall reaction pathways for dechlorination of TCE consume the hydrogen ion (Roberts et al. 1996; Arnold and Roberts 2000), thereby increasing the $\mathrm{pH}$ values in the reactor. Moreover, the nZVI also reacts with the DO in a rapid iron corrosion reaction, which decreases the DO value (Matheson and Tratnyek 1994). Therefore, ORP, DO, and pH should have great potential to be the control parameters in the nZVI process for TCE removal.

Artificial neural network (ANN) models, especially the back-propagation neural (BPN) network models, are highly effective in representing correlations between input and output parameters in complex, nonlinear systems. ANN models have been used in various applications to control the biological, chemical, and physical aspects of wastewater treatment processes (Khataeea and Kasiri 2010; Gamze et al. 2011; Curteanua et al. 2011). Thus, an ANN model was used in this study to attain more effective control of the nZVI process. This study was conducted at National United University, Miao-Li, Taiwan, and it was completed in August 2012.

\section{Materials and methods}

The nZVI process and TCE wastewater

Figure 1 shows the stainless steel, batch-type, laboratoryscale, cylindrical, nZVI reactor and the monitoring and control units that were set up in this study. The effective volume of the reactor was $4.0 \mathrm{~L}\left(133.3 \mathrm{~cm}^{2}\right.$ cross-sectional area with a height of $30 \mathrm{~cm}$ ). The top of the reactor was sealed to prevent the leakage of TCE; a mechanical mixer was installed in the reactor to provide sufficient mixing (200 rpm). The nZVI that was used was synthesized in the laboratory using a simple sodium borohydride reduction method (Shu et al. 2010; Ryu et al. 2011). A $0.45 \mathrm{M}$ iron chloride solution $\left(\mathrm{FeCl}_{3} \cdot 6 \mathrm{H}_{2} \mathrm{O}\right.$, J. T. Baker, USA) was added dropwise into a $0.25 \mathrm{M}$ sodium borohydride solution $\left(\mathrm{NaBH}_{4}\right.$, J. T. Baker, USA) with high-speed stirring at $500 \mathrm{rpm}$ without temperature and $\mathrm{pH}$ adjustments. According to the image from the scanning electron microscope (SEM), the typical particle sizes of this synthesized nZVI were approximately 100-120 nm. The $\mathrm{X}$-ray diffraction (XRD) analysis showed a peak at $2 \theta=44.87^{\circ}$.

One pH probe (Mettler-Toledo, Switzerland), one ORP probe with an $\mathrm{Ag} / \mathrm{AgCl}$ electrode (Mettler-Toledo, Switzerland), and one DO probe (InPro 6050, Mettler-Toledo, Switzerland) were installed in the nZVI reactor for online monitoring of ORP, $\mathrm{DO}$, and $\mathrm{pH}$ during the degradation of the TCE. All probes, meters, and dosing pumps (peristaltic
Fig. 1 Schematic diagram of the batch nZVI reactor and monitoring system in this study

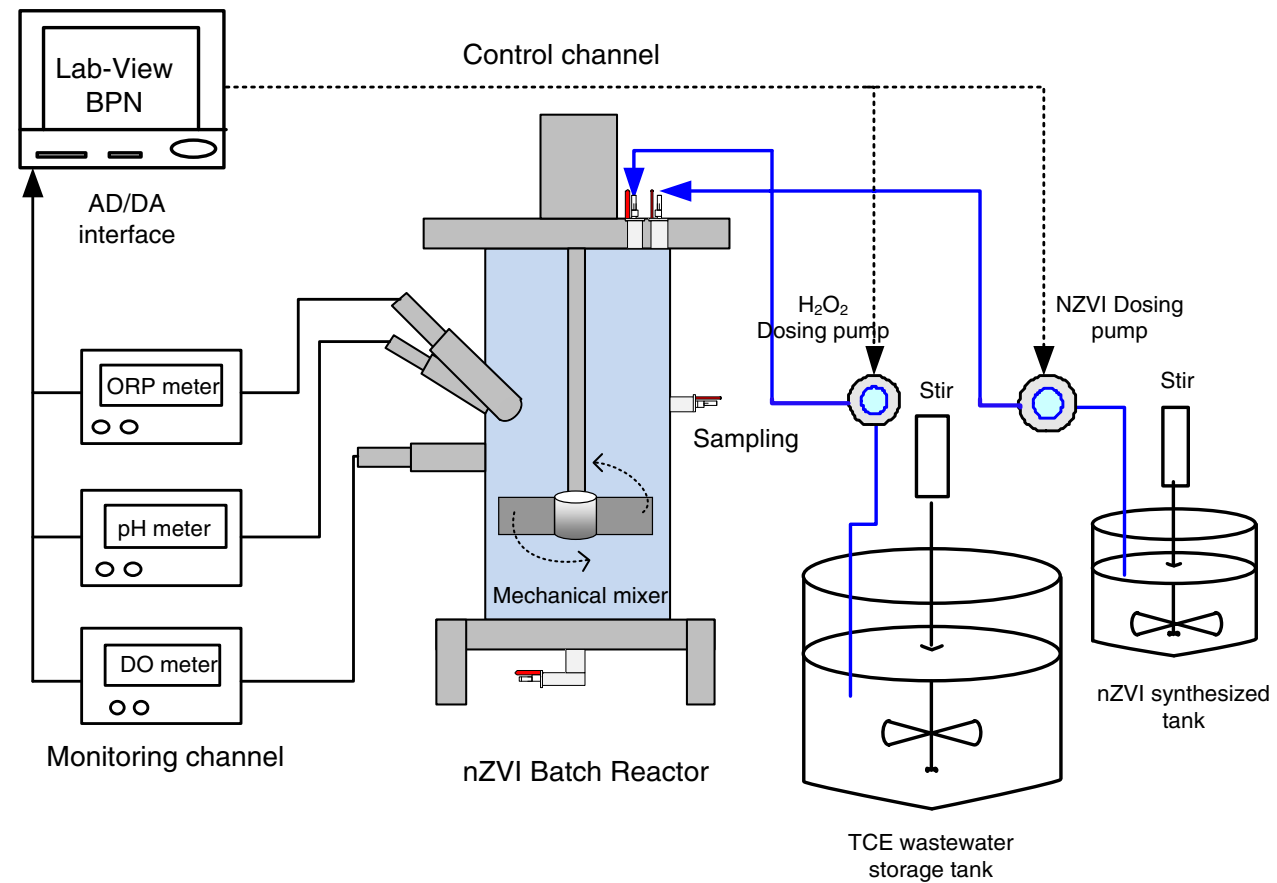


microtubing pumps) (Masterflex, USA) were connected to a personal computer (PC). LabVIEW 7.1 software (National Instruments, USA) was utilized for online data acquisition and dosage control.

Synthetic TCE wastewater was prepared by diluting analysis grade TCE $\left(\mathrm{C}_{2} \mathrm{HCl}_{3} \geqq 95 \%\right.$, Merck, Germany) with distilled water (SUNTEX WS-400, Taiwan). Four solutions were prepared with initial concentrations of TCE of $50,100,250$, and $500 \mathrm{mg} / \mathrm{L}$.

\section{Experiments for TCE degradation}

Batch TCE degradation experiments were conducted in a stainless steel cylinder. A preparation of $4.0 \mathrm{~L}$ of synthetic TCE wastewater was pumped into the reactor; the mechanical mixer was activated, and the synthesized nZVI was subsequently pumped into the reactor. The four different initial concentrations of influent TCE were controlled as 50, 100, 250, and $500 \mathrm{mg} / \mathrm{L}$. Seven and nine different nZVI doses, ranging from 0.1 to $2.0 \mathrm{~g} / \mathrm{L}$, were controlled for in different initial TCE concentrations. For the complete 3 -h reaction time, samples were extracted every $10-15 \mathrm{~min}$ for the analysis of the residual TCE concentrations and chlorine ion content.

The TCE concentration was analyzed using a gas chromatograph (Agilent 6890N, USA) with a flame ionization detector (GC-FID) and a capillary column (Agilent, DB-5, USA). The samples were injected through an autosampler (Agilent, 7693A, USA) with an injector port temperature of $250{ }^{\circ} \mathrm{C}$. The carrier gas was ultra-pure nitrogen at a flow of $50 \mathrm{~mL} / \mathrm{min}$, and the detector fuel gases were hydrogen and air, with flow rates of $40 \mathrm{~mL} / \mathrm{min}$ and $450 \mathrm{~mL} / \mathrm{min}$, respectively. The oven temperature was set at $45{ }^{\circ} \mathrm{C}$ for $3 \mathrm{~min}$, and then it was increased at the rate of $8{ }^{\circ} \mathrm{C} / \mathrm{min}$ until the temperature reached $220{ }^{\circ} \mathrm{C}$, where it was maintained for $15 \mathrm{~min}$. The chloride ion concentration in the reactor was measured using an ion chromatograph (IC, Dionex, ICS-1000) with an Ion-Pac AS12A column, and suppressed conductivity was used as the detector. The ORP, $\mathrm{pH}$, and DO values in the reactor were monitored online throughout all of the reactions.

\section{Results and discussion}

Characteristics of TCE degradation by nZVI

In the batch TCE degradation experiments, synthetic TCE wastewater samples were used that contained four different initial TCE concentrations of 50, 100, 250, and $500 \mathrm{mg} / \mathrm{L}$. Seven nZVI doses, ranging from 0.1 to $1.5 \mathrm{~g} / \mathrm{L}$ at $0.25 \mathrm{~g} / \mathrm{L}$ intervals, were used to treat the samples that contained low initial TCE concentrations of 50 and $100 \mathrm{mg} / \mathrm{L}$, and nine
Table 1 Detail experimental conditions for the TCE degradation by nZVI

Initial TCE concentrations nZVI dose $(\mathrm{g} / \mathrm{L})$

$(\mathrm{mg} / \mathrm{L})$

\begin{tabular}{ll}
\hline 50,100 & $0.10,0.25,0.50,0.75,1.0,1.25$, and 1.50 \\
200,500 & $0.10,0.25,0.50,0.75,1.0,1.25,1.50$, \\
& 1.75, and 2.00
\end{tabular}

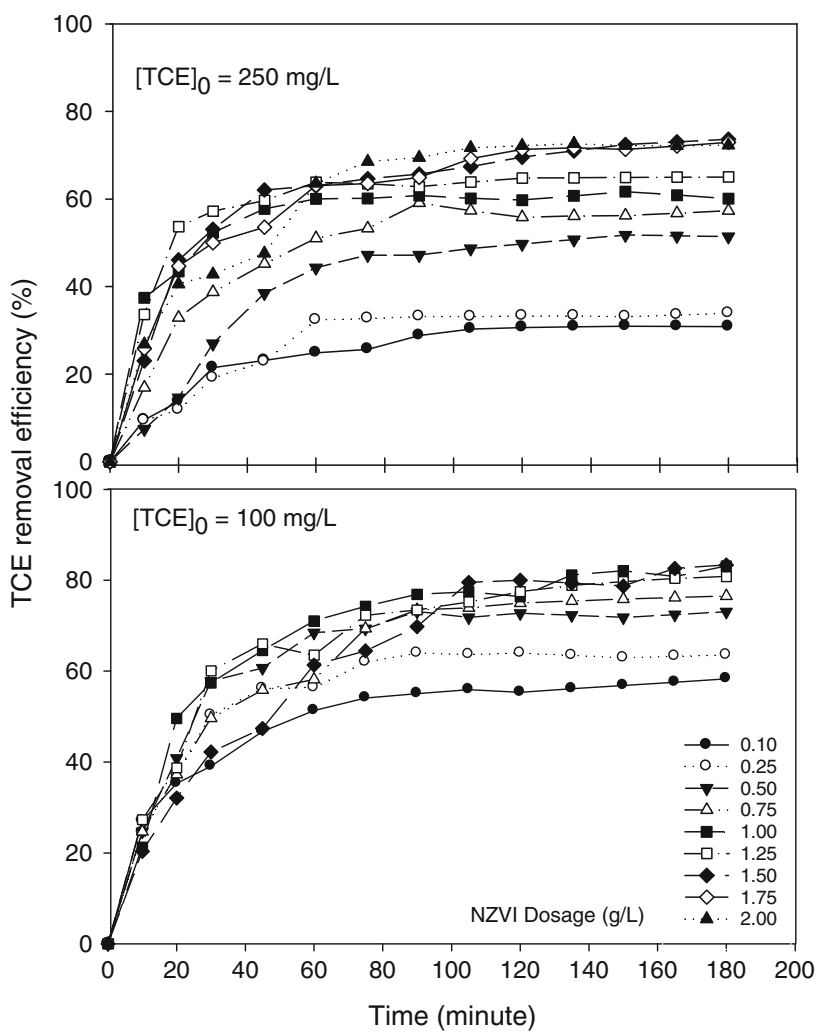

Fig. 2 Typical trends of TCE degradations under different initial TCE concentrations and various nZVI dosages

different nZVI doses, ranging from 0.1 to $2.0 \mathrm{~g} / \mathrm{L}$, also in $0.25 \mathrm{~g} / \mathrm{L}$ intervals, were used to treat the samples with higher TCE concentrations of 250 and $500 \mathrm{mg} / \mathrm{L}$. Table 1 lists the detailed experimental conditions for the batch TCE degradations by $n Z V I$.

Typical trends of TCE degradation using different initial TCE concentrations and various nZVI dosages are presented in Fig. 2. The TCE concentrations decreased rapidly during the initial degradation stage after the nZVI was added to the reactor. After a reaction time of approximately $120 \mathrm{~min}$, the degradation of TCE slowed and became stable, indicating that the degradation of TEC by nZVI was essentially completed. The removal efficiencies of TCE increased as the dosages of nZVI increased. For the initial TCE concentrations of 500 and $250 \mathrm{mg} / \mathrm{L}$, the TCE degradations were 


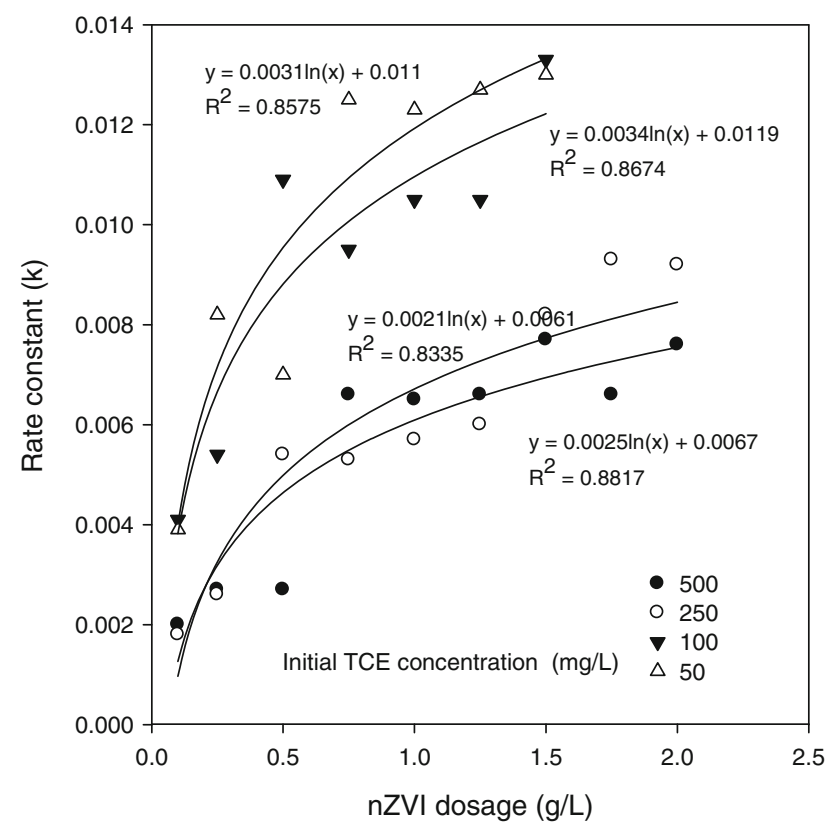

Fig. 3 Correlations between rate constants $(k)$ of TCE degradations with nZVI doses

approximately 70 and $73 \%$, respectively, for nZVI doses of $1.5 \mathrm{~g} / \mathrm{L}$. The TCE degradation did not significantly increase when the nZVI doses surpassed $1.75 \mathrm{~g} / \mathrm{L}$. However, the TCE degradations for the relatively lower initial TCE concentration of $50 \mathrm{mg} / \mathrm{L}$ reached approximately $94 \%$ when the nZVI doses were $1.5 \mathrm{~g} / \mathrm{L}$.

The kinetics of the TCE degradation by nZVI in this study typically followed the pseudo-first-order model (Cho and Choi 2010; Matheson and Tratnyek 1994). Figure 3 shows the correlations between the rate constants $(k)$ of the TCE degradations and the nZVI doses in this study. The rate constants of the TCE degradations increased logarithmically as the nZVI doses and the initial TEC concentration.

In the degradation of TCE, the dechlorination reaction of TCE by nZVI yields a chloride ion (Matheson and Tratnyek 1994). Some byproducts, such as 1,1-dichloroethene (1,1-DCE), trans-DCE, and cis-DCE, were formed in this reductive dechlorination of TCE. Finally, most of these byproducts can be converted to ethane, vinyl chloride, ethylene, or some other final products. Typically, the TCE degradation by nZVI can be presented stoichiometrically as shown in the following equation ( $\mathrm{Li}$ et al. 2012):

$\mathrm{HClC}=\mathrm{CCl}_{2}+4 \mathrm{Fe}^{0}+5 \mathrm{H}_{2} \mathrm{O}$

$$
\rightarrow \mathrm{H}_{3} \mathrm{C}-\mathrm{CH}_{3}+4 \mathrm{Fe}^{2+}+5 \mathrm{OH}^{-}+3 \mathrm{Cl}^{-}
$$

According to Eq. (1), three moles of the chloride ion theoretically will be produced when one mole of TEC is degraded by nZVI; therefore, the amount of chloride ions yielded in the reaction is another critical indicator of TCE

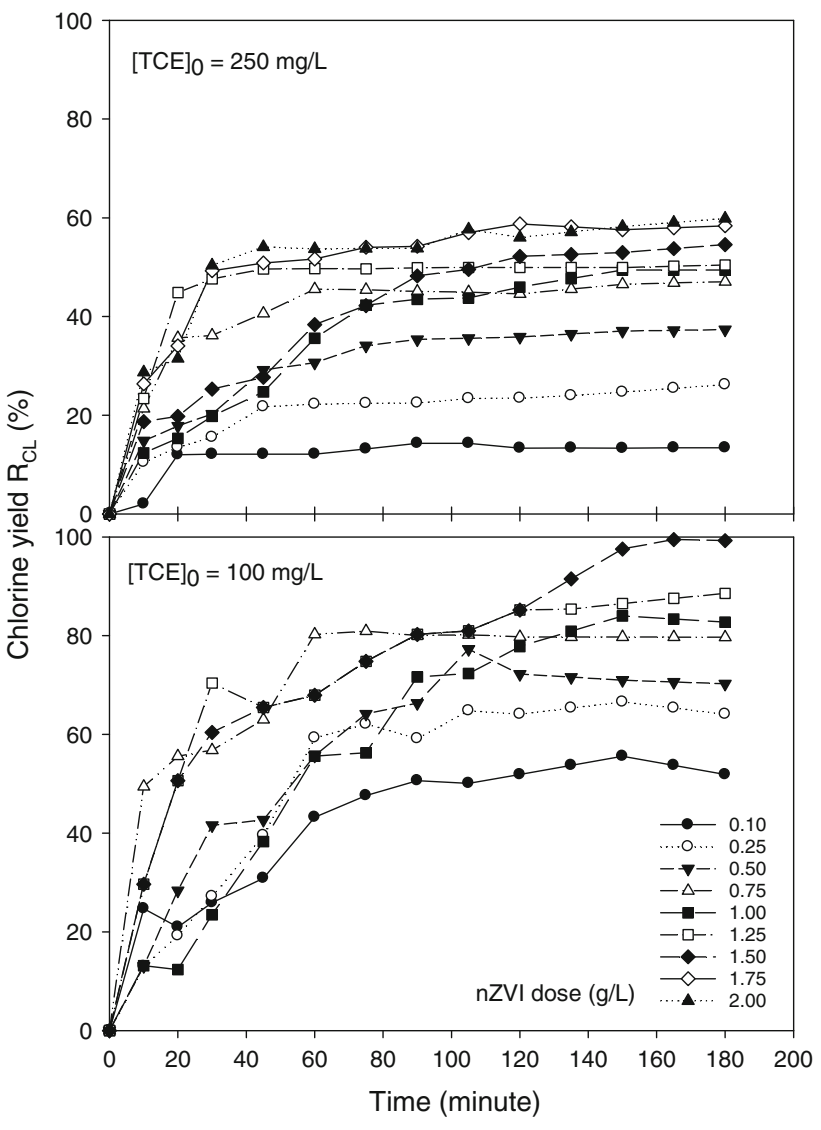

Fig. 4 Typical trends of chlorine yield $\left(R_{\mathrm{Cl}}\right)$ under different initial TCE concentrations and various nZVI dosages

degradation. Figure 4 presents the ratio of the measured chloride ion yield to the theoretical chloride ion yield $\left(R_{\mathrm{Cl}}\right)$ for TCE degradation at different nZVI doses and different initial TCE concentrations. The values of $R_{\mathrm{Cl}}$ increase as $\mathrm{nZVI}$ doses increase, as does the reaction time for the TCE degradation with the same initial TCE concentration. The tendency of chloride ion variations presented similar trends of TCE degradations. As the nZVI doses increased to approximately $1.5 \mathrm{~g} / \mathrm{L}$, the $R_{\mathrm{Cl}}$ reached approximately 88 and $90 \%$ for the experiments with initial TCE concentrations of 100 and $50 \mathrm{mg} / \mathrm{L}$, respectively. However, the $R_{\mathrm{Cl}}$ only reached about 60 to $70 \%$ for the experiments that had the same nZVI dose of $1.5 \mathrm{~g} / \mathrm{L}$ but had relatively greater initial TCE concentrations of 250 and $500 \mathrm{mg} / \mathrm{L}$. These reaction conditions also resulted in relatively lower TCE degradations. These results are similar to those of other studies (Cho and Choi 2010; Matheson and Tratnyek 1994), indicating that chemical reduction is the major mechanism of TCE degradation by nZVI.

Variations in $\mathrm{pH}, \mathrm{ORP}$, and $\mathrm{DO}$

Figure 5 presents the typical variations in $\mathrm{pH}$, ORP, and DO in this study during the batch experiments of TCE 

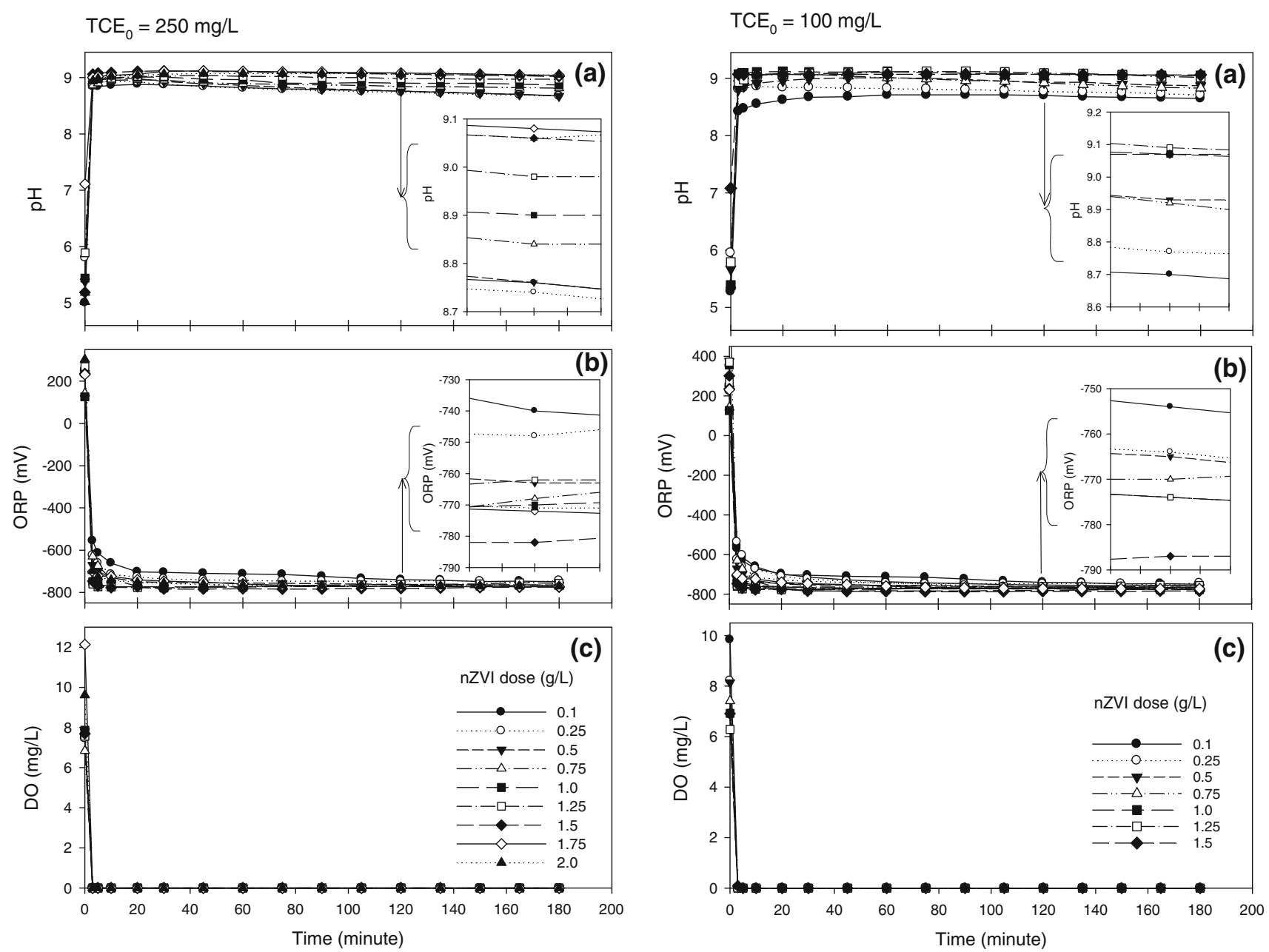

Fig. 5 Variations of pH, ORP and DO in the nZVI process for TCE degradation under different initial TCE concentrations and various nZVI dosages

degradation by nZVI. According to Eq. (1), hydroxyl ions were released as the TCE was degraded. The general reaction of dissolving metal reduction will consume the hydrogen ions, as indicated in Eq. (2); the nZVI will also react with the DO in the aqueous solution and release hydroxyl ions, as shown in Eq. (3). In water at anaerobic conditions, nZVI will corrode and release hydroxyl ions, as shown in Eq. (4), and the primary production of ferrous iron from nZVI will undergo further oxidation reaction and be converted to ferric iron, which also produces hydroxyl ions, as shown in Eq. (5) (Cho and Choi 2010; Crane and Scott 2012; Matheson and Tratnyek 1994).

$$
\begin{aligned}
& \mathrm{Fe}^{0}+\mathrm{RX}+\mathrm{H}^{+} \rightarrow \mathrm{Fe}^{2+}+\mathrm{RH}+\mathrm{X}^{-} \\
& \mathrm{Fe}^{0}+2 \mathrm{H}_{2} \mathrm{O} \rightarrow \mathrm{Fe}^{2+}+\mathrm{H}_{2}+2 \mathrm{OH}^{-}
\end{aligned}
$$

$2 \mathrm{Fe}^{0}+\mathrm{O}_{2}+2 \mathrm{H}_{2} \mathrm{O} \rightarrow 2 \mathrm{Fe}^{2+}+4 \mathrm{OH}^{-}$

$2 \mathrm{Fe}^{2+}+2 \mathrm{H}_{2} \mathrm{O} \rightarrow 2 \mathrm{Fe}^{3+}+\mathrm{H}_{2}+2 \mathrm{OH}^{-}$

Due to the many reactions associated with the degradation of TCE by nZVI that result in increased $\mathrm{pH}$, the monitored $\mathrm{pH}$ in the reactor increased significantly as nZVI was added. Figure 5a shows the variations of $\mathrm{pH}$ during the batch TCE degradation experiment. The $\mathrm{pH}$ values increased rapidly, from 7.0 (near neutral) to as high as $8.5-9.5$ as the nZVI was added to the reactor. Subsequently, the monitored $\mathrm{pH}$ underwent a slight decrease. Greater increases of the $\mathrm{pH}$ values also were observed when greater dosages of nZVI were added in the experiments that had the same initial TCE concentration. 


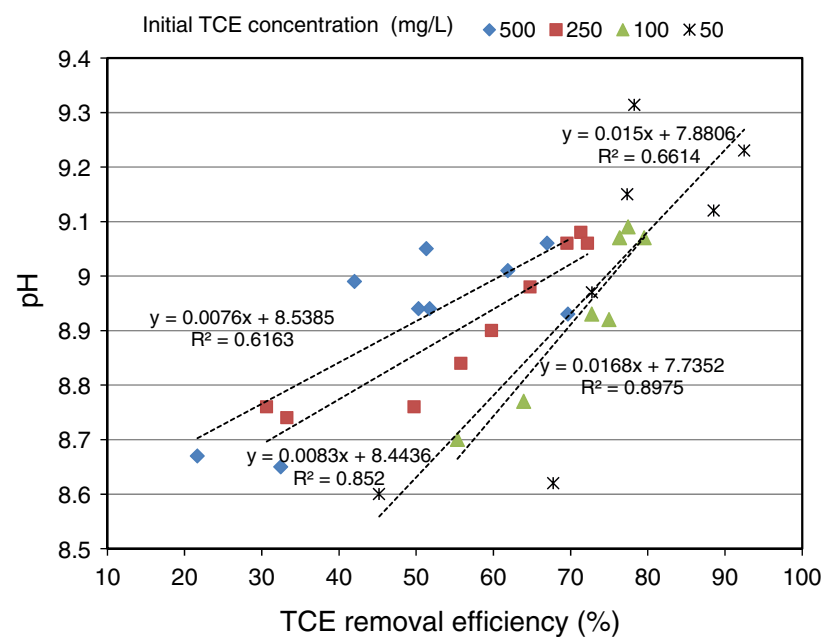

Fig. 6 Correlations between TCE removal efficiencies and monitoring $\mathrm{pH}$ values

Because the nZVI has a very strong reductive capacity with the standard potential of $-0.440 \mathrm{~V}$, the ORP monitored in the batch experiment decreased sharply from the range of +220 to $+250 \mathrm{mV}$ down to the range of -670 to $-810 \mathrm{mV}$ as nZVI was added (Fig. 5b). ORP typically was decreased by the increased addition of nZVI in the experiments with the same initial TCE concentration.

Dissolved oxygen in the aqueous solution is a typical oxidant for accepting the electrons released from nZVI corrosion in water, as shown in Eq. (4). In a typical nZVI treatment system, the amount of released electrons from nZVI was always much higher than the concentration of DO, an electron accepter, in the reactor. The monitored DO dropped rapidly, i.e., within $3 \mathrm{~min}$, to zero for all the batch experiments as nZVI was added (Fig. 5c). The nZVI dosages were $0.1-2.0 \mathrm{~g} / \mathrm{L}$, while the initial DO concentrations in the reactor were only around $8.0 \mathrm{mg} / \mathrm{L}$ in this study. The fact that the DO decreased to zero indicated that the electrons released from nZVI were much greater than those accepted by the DO.

The observed variations of $\mathrm{pH}$ and ORP have theoretical correlations with the TCE degradations by the nZVI, meaning that the values or trends of monitoring $\mathrm{pH}$ and ORP should present meaningful correlations with TCE degradations. According to the variations in the TCE degradations and chloride ion yields in the previous batch experiments, the duration of $120 \mathrm{~min}$ provided a proper reaction time for the nZVI process in this study. Thus, the $\mathrm{pH}$ and ORP values at a reaction time of 120 min were correlated with the efficiency of the TCE degradation. Figure 6 shows the correlations of $\mathrm{pH}$ values to TCE removal efficiencies, at $120 \mathrm{~min}$, for different initial TCE concentrations of 50, 100, 250, and $500 \mathrm{mg} / \mathrm{L}$. Typically, linear relationships were observed, and greater TCE degradations were achieved by the

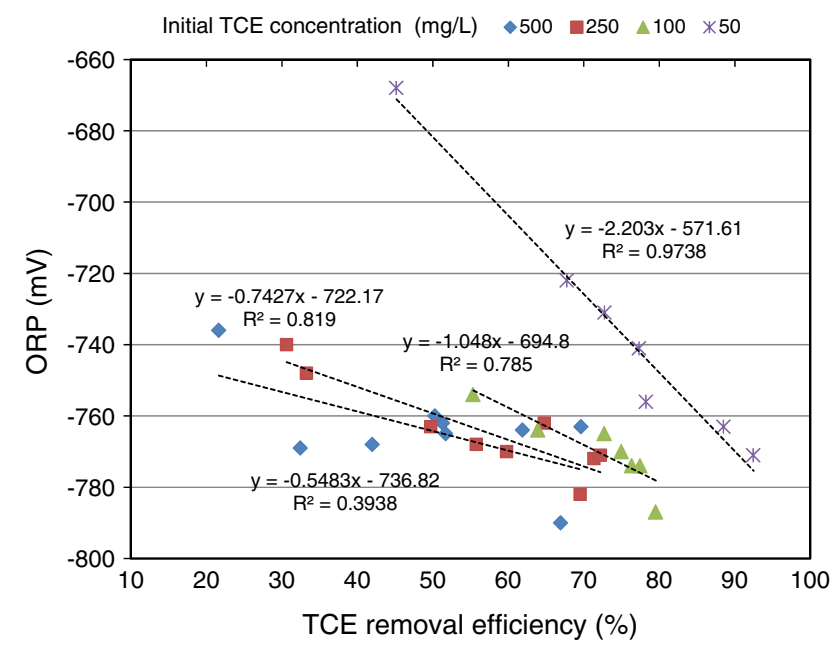

Fig. 7 Correlations between TCE removal efficiencies and monitoring ORP values

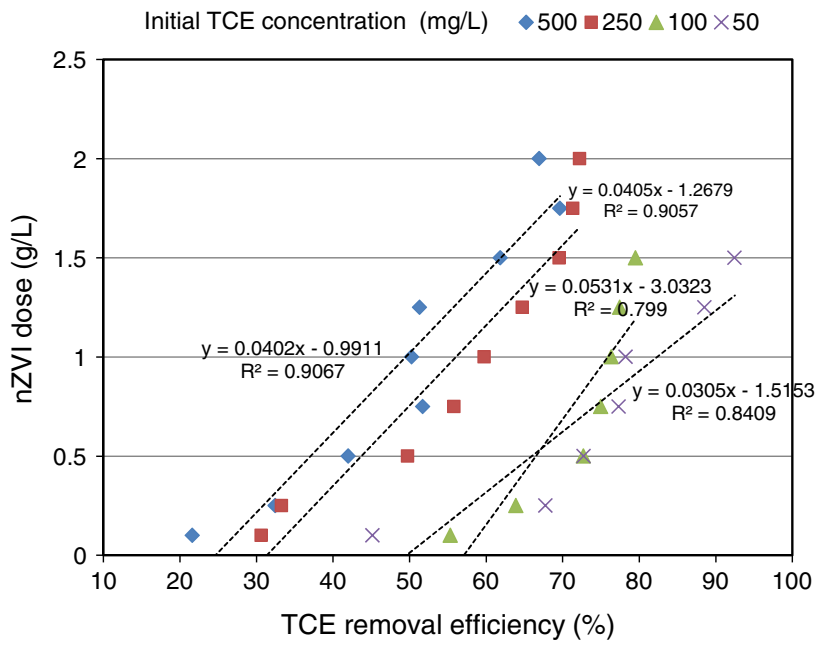

Fig. 8 Correlations between TCE removal efficiencies and nZVI dosages

experiments that had greater increases in $\mathrm{pH}$ caused by the dosing of nZVI. This finding agrees with the basic information gleaned from Eqs. (1) through (5).

Figure 7 presents the relationships between the monitored ORP values and the TCE removal efficiencies at a reaction time of $120 \mathrm{~min}$ for different nZVI doses and initial TCE concentrations. The degradation of TCE increased in these experiments with lower ORP values due to the higher nZVI dosing, indicating that more reductive conditions were achieved.

Similar correlations between TCE degradations with the monitored ORP and $\mathrm{pH}$ values also were observed in the batch experiments at a reaction time of $90 \mathrm{~min}$ (data not 

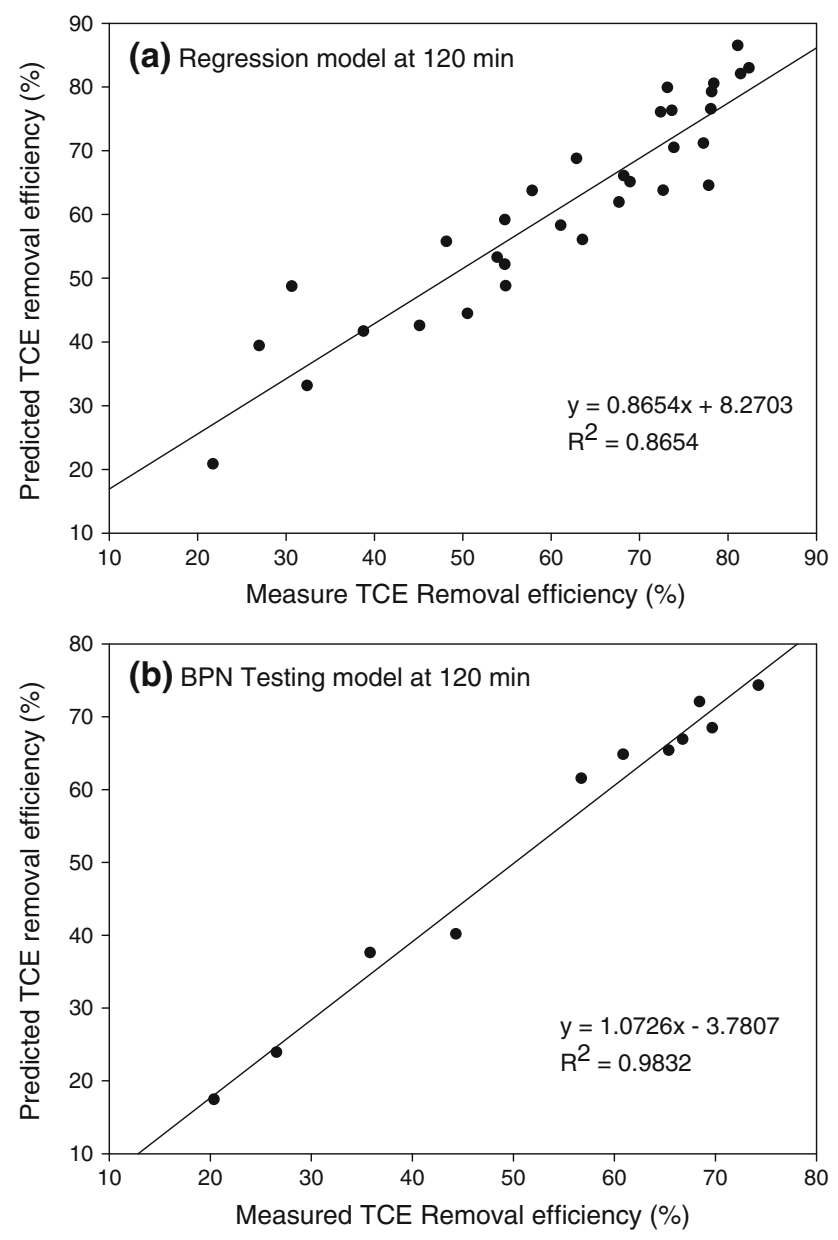

Fig. 9 Relationships between measured TCE removal efficiencies with the predicted TCE removal efficiencies of a regression model and $\mathbf{b}$ BPN model

shown). As a result, the monitored ORP and $\mathrm{pH}$ values presented meaningful correlations with the TCE removal efficiencies.

Development of an nZVI control model for TCE degradation

The main function of the control model for wastewater treatment was to construct correlations between the monitored and controlled parameters for process operations. According to the experimental results, the monitored ORP and $\mathrm{pH}$ values have meaningful correlations with the TCE removal efficiencies, which means that these values have great potential to be the control parameters for the process in which TCE is degraded by nZVI. Also, the nZVI dosage is one of the major operational costs for a typical nZVI process, and Fig. 8 shows that this dosage presented close correlations with TCE removal efficiencies in this study.
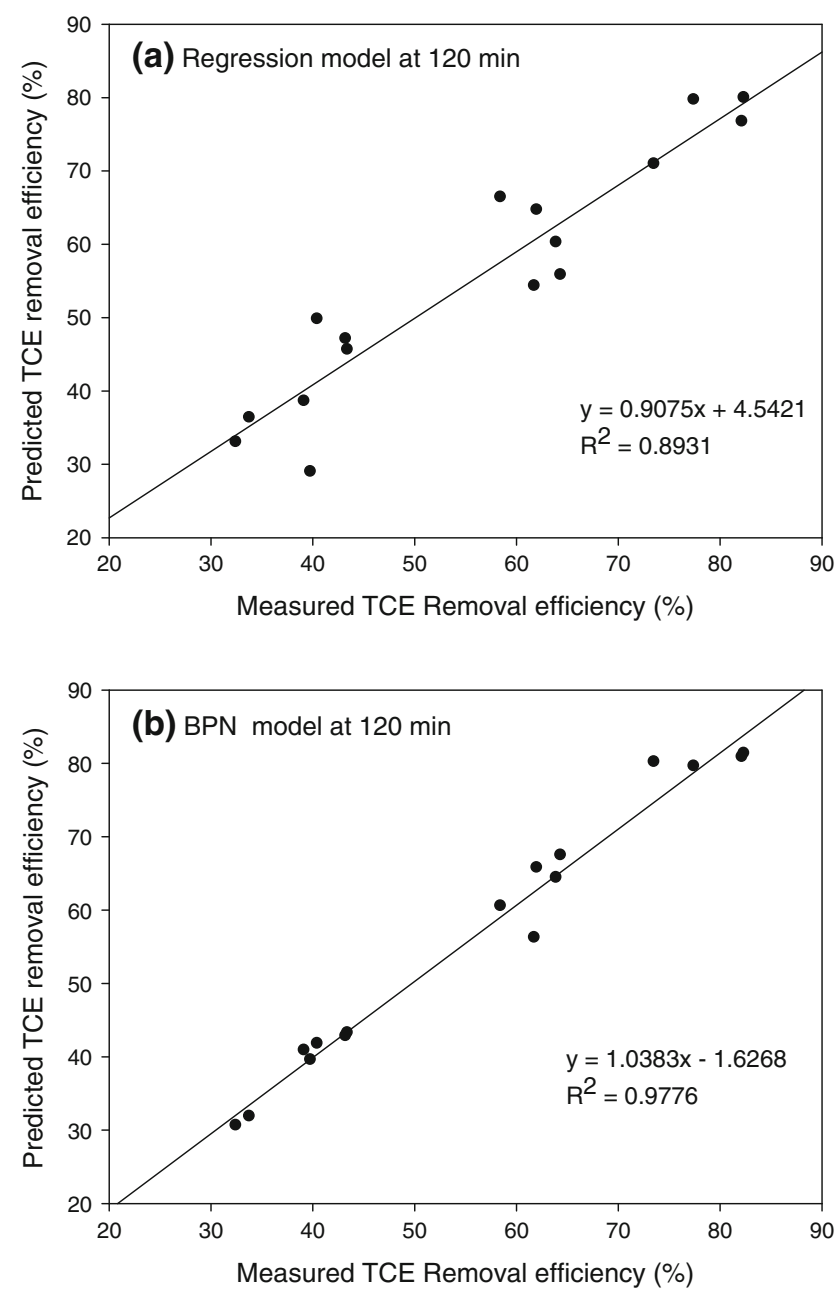

Fig. 10 Relationships between measured TCE removal efficiencies with predicted TCE removal efficiencies by a regression model and b BPN model for the verification experiments

Developing a control model for TCE degradation by the nZVI process is critical for optimizing the process operations. According to the previous experiments, the reaction time of $120 \mathrm{~min}$ was an appropriate duration for the degradation of TCE; thus, the monitored $\mathrm{pH}$ and ORP at a reaction time of $120 \mathrm{~min}$, the initial concentration of TCE, and the dosages of nZVI were used as the input parameters to predict TCE removal efficiency in this study.

Two types of models, i.e., a multiple regression model and an ANN model, were used in this study. A total of 32 runs of datasets from the previous TCE degradation experiments were used to construct the control models. For the multiple regression model, an acceptable prediction result of TCE removal efficiency with a correlation coefficient $R^{2}$ of 0.8654 was achieved, as presented in Eq. (6) and shown in Fig. 9a. Compared to the trends of TCE 
degradations in previous experimental results, the model presented trends of TCE degradations that were similar to the trends of the variations in ORP, $\mathrm{pH}$, and the nZVI dosage [Eq. (6)].

$$
\begin{aligned}
& \text { TCE degradation efficiency }(\%) \\
& \begin{aligned}
= & -0.06749(\text { Initial TCE conc. })+0.014494(\mathrm{nZVI} \text { dose }) \\
& -0.18052(\mathrm{ORP})+10.93218(\mathrm{pH})-170.236
\end{aligned}
\end{aligned}
$$

Given that only one acceptable prediction result was provided by the regression model, the BPN network model was used to develop the nZVI control model for a more precise prediction of TCE degradation. A typical BPN model consists of three layers, i.e., input, hidden, and output layers. These three layers were applied, and the same datasets were used that were used with the regression model. The BPN model uses the generalized delta learning rule as its training algorithm, the gradient descent method to minimize error, the sigmoid function as the activation function, and root mean square (RMS) to evaluate the performances of the training and test procedures ( $\mathrm{Yu}$ et al. 2009b).

Very precise prediction results of TCE removal efficiencies were defined by the BPN model, with a correlation coefficient $R^{2}$ of 0.9832 , as shown in Fig. 9b. The BPN model presented much more precise prediction results of the TCE degradation than the regression model, indicating that the BPN model has a greater potential to be a control model for the nZVI process.

Finally, another 16 runs of TCE degradation experiments having similar conditions to the previous 32 runs of experiments were conducted to validate the prediction of TCE removal efficiencies by the BPN model. Figure 10 shows the very good linear relationship that was found between the measured TCE removal efficiencies and those predicted by the BPN model.

According to the batch TCE degradation experiments, a duration of $90 \mathrm{~min}$ would be another possible retention time that could be selected for increasing the capacity of the nZVI reactor. Therefore, similar regression modeling and BPN modeling also were conducted for similar datasets of ORP, $\mathrm{pH}$, nZVI dosage, initial TCE concentration, and TCE removal efficiency observed in the batch experiments conducted for a reaction time of $90 \mathrm{~min}$. The results of the models also were similar. The BPN model presented very precise prediction results for TCE removal efficiencies, with an $R^{2}$ of 0.97 , which was also much higher than the $R^{2}$ of 0.84 from the regression model (data not shown).

The experimental results showed that both the regression model and the BPN model demonstrated good capabilities of correlating the relationships among monitored
OPR, $\mathrm{pH}$, initial TCE concentration, nZVI dosages, and TCE removal efficiencies, making them potentially useful for controlling the nZVI process for TCE degradation.

\section{Conclusion}

This study presents the development of a control model for the nZVI process for TCE degradation using online monitoring of ORP and $\mathrm{pH}$. The experimental results indicated that the TCE degradations can reach approximately $94 \%$ for the experiments with nZVI doses of $1.5 \mathrm{~g} / \mathrm{L}$ and an initial TCE concentration of $50 \mathrm{mg} / \mathrm{L}$. Lower TCE degradations were found for the initial TCE concentrations over $250 \mathrm{mg} / \mathrm{L}$. The duration of $120 \mathrm{~min}$ would be an appropriate reaction time for the nZVI process. The monitoring of ORP and $\mathrm{pH}$ in the reactor presented good correlations with the TCE degradation at this reaction time. Thus, the monitoring of $\mathrm{pH}, \mathrm{ORP}$, initial TCE concentration, and nZVI dose were used as the input parameters to predict the TCE removal efficiency. The BPN model presented very precise prediction results for TCE removal efficiency, with an $R^{2}$ of 0.98 , which was much better than the $R^{2}$ of 0.86 for the regression model. Similar modeling results also were found for another possible reaction time of $90 \mathrm{~min}$. As a result, both the regression model and the BPN model have good capabilities to correlate the relationships among monitored OPR, $\mathrm{pH}$, initial TCE concentration, nZVI dosages, and TCE removal efficiencies, and they potentially can be used to control the nZVI process for TCE degradation.

Acknowledgments The authors thank the National Science Council of the Republic of China, Taiwan, for financially supporting this research under Contract No. NSC 100-2221-E-239-006-MY2.

\section{References}

Arnold WA, Roberts AL (2000) Pathways and kinetics of chlorinated ethylene and chlorinated acetylene reaction with $\mathrm{Fe}(0)$ particles. Environ Sci Technol 34:1794-1805

Chang CN, Cheng HB, Chao AC (2004) Applying the Nernst Equation to simulate redox potential variations for biological nitrification and denitrification processes. Environ Sci Technol 38:1807-1812

Cho Y, Choi SI (2010) Degradation of PCE, TCE and 1,1,1-TCA by nanosized FePd bimetallic particles under various experimental conditions. Chemosphere 81:940-945

Crane RA, Scott TB (2012) Nanoscale zero-valent iron: future prospects for an emerging water treatment technology. J Hazard Mater 211-212:112-125

Curteanua S, Piuleaca CG, Godinib K, Azaryanc G (2011) Modeling of electrolysis process in wastewater treatment using different types of neural networks. Chem Eng J 172:267-276 
Diao M, Yao M (2009) Use of zero-valent iron nanoparticles in inactivating microbes. Water Res 43:5243-5251

Dong T, Luo H, Wang Y, Hu B, Chen H (2011) Stabilization of FePd bimetallic nanoparticles with sodium carboxymethyl cellulose for catalytic reduction of para-nitrochlorobenzene in water. Desalination 271:11-19

Dua J, Lub J, Wu Q, Jing C (2012) Reduction and immobilization of chromate in chromite ore processing residue with nanoscale zero-valent iron. J Hazard Mater 215-216:152-158

Fuerhacker M, Bauer H, Ellinger R, Schmid H, Zibuschka F, Puxbaum H (2000) Approach for a novel control strategy for simultaneous nitrification/denitrification in activated sludge reactor. Water Res 34:2499-2506

Gamze TN, Mesci B, Ozgonenel O (2011) The use of artificial neural networks (ANN) for modeling of adsorption of $\mathrm{Cu}$ (II) from industrial leachate by pumice. Chem Eng J 171:1091-1097

Gernjak W, Fuerhacker M, Fernandez-Ibanez P, Blanco J, Malato S (2006) Solar photo-Fenton treatment-process parameters and process control. Appl Catal B Environ 64:121-130

Ghauch A, Tuqan A, Assi HA (2009) Antibiotic removal from water: elimination of amoxicillin and ampicillin by microscale and nanoscale iron particles. Environ Pollut 157:1626-1635

Haest PJ, Springael D, Seuntjens P, Smolders E (2012) Self-inhibition can limit biologically enhanced TCE dissolution from a TCE DNAPL. Chemosphere 81:1369-1375

He F, Zhao D, Liu J, Roberts CB (2007) Stabilization of Fe-Pd nanoparticles with sodium carboxymethyl cellulose for enhanced transport and dechlorination of trichloroethylene in soil and groundwater. Ind Eng Chem Res 46(1):29-34

Hua M, Zhang S, Pan B, Zhang W, Lv L, Zhang Q (2012) Heavy metal removal from water/wastewater by nanosized metal oxides: a review. J Hazard Mater 211-212:317-331

Khataeea AR, Kasiri MB (2010) Artificial neural networks modeling of contaminated water treatment processes by homogeneous and heterogeneous nanocatalysis. Mol Catal A Chem 331:86-100

Li S, Fang Y-L, Romanczuk CD, Jin Z, Li T, Wong MS (2012) Establishing the trichloroethene dechlorination rates of palladium-based catalysts and iron-based reductants. Appl Catal B Environ 125:95-102

Lin YT, Weng CH, Chen FY (2008) Effective removal of AB24 dye by nano/micro-size zero-valent iron. Sep Purif Technol 64:26-30

Lin CH, Yu RF, Cheng WP, Liu CR (2012) Monitoring and control of $\mathrm{UV}$ and $\mathrm{UV}-\mathrm{TiO}_{2}$ disinfections for municipal wastewater reclamation using artificial neural networks. J Hazard Mater 209-210:348-354

Liu HB, Chen TH, Chang DY, Chen D, Liu Y, He HP, Yuan P, Frost $R$ (2012) Nitrate reduction over nanoscale zero-valent iron prepared by hydrogen reduction of goethite. Mate Chem Phys 133:205-211

Lookman R, Bastiaens L, Borremans B, Maesen M, Gemoets J, Diels L (2004) Batch-test study on the dechlorination of 1,1,1trichloroethane in contaminated aquifer material by zero-valent iron. J Contam Hydrol 74:133-144

Lucas MS, Peres JA (2009) Removal of COD from olive mill wastewater by Fenton's reagent: KINETIC study. J Hazard Mater 168:1253-1259

Martin de la Vega PT, Martinez de Salazar E, Jaramillo MA, Cros J (2012) New contributions to the ORP \& DO time profile characterization to improve biological nutrient removal. Bioresour Technol 114:160-167
Matheson LJ, Tratnyek PG (1994) Reductive dehalogenation of chlorinated methanes by iron metal. Environ Sci Technol 28:2045-2053

Moon BH, Park YB, Park KH (2011) Fenton oxidation of Orange II by pre-reduction using nanoscale zero-valent iron. Desalination 268:249-252

Olsson G (2012) ICA and me-a subjective review. Water Res 46:1585-1624

Ortega-Gomez E, Ubeda JCM, Hervas JDA, Lopez JLC, Jorda LS-J, Perez JAS (2012) Automatic dosage of hydrogen peroxide in solar photo-Fenton plants: development of a control strategy for efficiency enhancement. J Hazard Mater 237-238:223-230

Roberts AL, Totten LA, Arnold WA, Burris DR, Campbell TJ (1996) Reductive elimination of chlorinated ethylenes by zero-valent metals. Environ Sci Technol 30:2654-2659

Ryu A, Jeong SW, Jang A, Choi H (2011) Reduction of highly concentrated nitrate using nanoscale zero-valent iron: effects of aggregation and catalyst on reactivity. Appl Catal B Environ 105:128-135

Saby S, Djafer M, Chen GH (2003) Effect of low ORP in anoxic sludge zone on excess sludge production in oxic-settling-anoxic activated sludge process. Water Res 37:11-20

Shi LN, Zhang X, Chen ZL (2010) Removal of Chromium (VI) from wastewater using bentonite-supported nanoscale zero-valent iron. Water Res 45:886-892

Shu HY, Chang MC, Yu HH, Chen WH (2007) Reduction of an azo dye Acid Black 24 solution using synthesized nanoscale zerovalent iron particles. J Colloid Inter Sci 314:89-97

Shu HY, Chang MC, Chen CC, Chen PE (2010) Using resin supported nano zero-valent iron particles for decoloration of Acid Blue 113 azo dye solution. J Hazard Mater 184:499-505

Smuleac V, Varma R, Sikdar S, Bhattacharyya D (2011) Green synthesis of $\mathrm{Fe}$ and $\mathrm{Fe} / \mathrm{Pd}$ bimetallic nanoparticles in membranes for reductive degradation of chlorinated organics. J Membrane Sci 379:131-137

Uzuma C, Shahwan T, Eroglu AE, Lieberwirth I, Scott TB, Hallam KR (2008) Application of zero-valent iron nanoparticles for the removal of aqueous $\mathrm{Co}^{2+}$ ions under various experimental conditions. Chem Eng J 144:213-220

Wang Q, Jeong S-W, Choi H (2012) Removal of trichloroethylene DNAPL trapped in porous media using nanoscale zerovalent iron and bimetallic nanoparticles: direct observation and quantification. J Hazard Mater 213-214:299-310

West MR, Grant GP, Gerhard JI, Kueper BH (2008) The influence of precipitate formation on the chemical oxidation of TCE DNAPL with potassium permanganate. Adv Water Res 31:324-338

Won SG, Ra CS (2011) Biological nitrogen removal with a real-time control strategy using moving slope changes of $\mathrm{pH}(\mathrm{mV})-$ and ORP-time profiles. Water Res 45:171-178

Yu RF, Liaw SL, Cheng WY, Chang CN (2000) Performance enhancement of SBR applying real-time control. J Environ Eng ASCE 126:943-948

Yu RF, Chen HW, Cheng WP, Shen YC (2009a) Application of pHORP titration to dynamically control the chlorination and dechlorination for wastewater reclamation. Desalination 244:164-176

Yu RF, Chen HW, Cheng WP, Hsieh PH (2009b) Dosage control of Fenton process for color removal of textile wastewater applying ORP monitoring and artificial neural network. J Environ Eng ASCE 135:325-332 
Zanetti L, Frison N, Nota E, Tomizioli M, Bolzonella D, Fatone F (2012) Progress in real-time control applied to biological nitrogen removal from wastewater. A short-review. Desalination 286:1-7
Zhang X, Lin S, Lu XQ, Chen ZL (2010) Removal of Pb(II) from water using synthesized kaolin supported nanoscale zero-valent iron. Chem Eng J 163:243-248 